University of Wollongong

Research Online

Faculty of Social Sciences - Papers (Archive) Faculty of Arts, Social Sciences \& Humanities

2017

Engagement and Qualitative Interviewing: An Ethnographic Study of the Use of Social Media and Mobile Phones Among Remote Indigenous Youth

Kishan A. Kariippanon

University of Wollongong, kishan@uow.edu.au

Kate Senior

University of Wollongong, ksenior@uow.edu.au

Follow this and additional works at: https://ro.uow.edu.au/sspapers

Part of the Education Commons, and the Social and Behavioral Sciences Commons

Research Online is the open access institutional repository for the University of Wollongong. For further information contact the UOW Library: research-pubs@uow.edu.au 


\title{
Engagement and Qualitative Interviewing: An Ethnographic Study of the Use of Social Media and Mobile Phones Among Remote Indigenous Youth
}

\author{
Abstract \\ In 2012, Kishan Kariippanon began an ethnographic study on the use of social media and mobile phones \\ by Indigenous youth practicing traditional culture in a remote community in Northern Australia. A prepaid \\ mobile phone service is available in most Northern Territory remote Indigenous communities. This case \\ study provides an account of the vital practical steps for engagement and conducting qualitative \\ interviewing in an Indigenous community where traditional structure of kinship and communications is \\ practiced. The case sheds light on the particular challenge of gaining trust and building an authentic \\ relationship with individuals and the community as part of the engagement process and culturally \\ appropriate interviewing technique.

\section{Keywords} \\ mobile, phones, among, remote, indigenous, youth, qualitative, engagement, interviewing:, ethnographic, \\ study, social, media

\section{Disciplines} \\ Education | Social and Behavioral Sciences

\section{Publication Details} \\ Kariippanon, K. \& Senior, K. (2017). Engagement and Qualitative Interviewing: An Ethnographic Study of \\ the Use of Social Media and Mobile Phones Among Remote Indigenous Youth. SAGE Research Methods \\ Cases, 1-15.
}




\section{Engagement \& Qualitative Interviewing: An}

\section{Ethnographic Study of the Use of Social Media}

and Mobile Phones Amongst remote

\section{Indigenous Youth}

\section{Kishan Kariippanon}

University of Wollongong, Australia

Kishan@uow.edu.au

\section{Kate Senior}

University of Wollongong, Australia

Keywords

Aboriginal, Yolngu, Facebook, YouTube, media, communications, history, culture, oral history, cultural protocols, kinship

\section{Relevant Disciplines}

Anthropology, Public Health

\section{Methods Used}

In-depth interviews, Participant observation, Ethnography

\section{Academic Level}

Intermediate Undergraduate, Advanced Undergraduate, Postgraduate

Kate Senior is a medical anthropologist and holds an Australian Research Council Future

Fellowship to explore young people's lived experiences of the social determinants of health. She is an Associate Professor of public health in the school of Health and Society at the University of Wollongong and an honorary fellow at the Menzies School of Health Research, 


\begin{abstract}
In 2012, Kishan Kariippanon began an ethnographic study on the use social media and mobile phones by Indigenous youth, practicing traditional culture in a remote community in Northern Australia. A prepaid mobile phone service is available in most Northern Territory remote Indigenous communities. This case study provides an account of the vital practical steps for engagement and conducting qualitative interviewing in an Indigenous community where traditional structure of kinship and communications is practiced. The case sheds light on the particular challenge of gaining trust and building an authentic relationship with individuals and the community as part of the engagement process and culturally appropriate interviewing technique.
\end{abstract}

\title{
Learning Outcomes
}

By the end of the case, you should:

- Learn about Indigenous participants’ use of social media and mobile phones.

- Understand that interviewing Indigenous people require building trust and rapport.

- Understand that ethnographic study requires going deep into the community, immersing in community life and paying attention to details.

- Understand the role of participant observation as a tool for in-depth interview sampling.

\section{Project Overview and Context}

Since 2010 the use of Facebook, YouTube, Twitter and blogs have become a platform to attract and engage young people in public health outreach efforts (Eysenbach 2008). The literature from Australia and globally on the use of social media to engage young people to create behavior change is insufficient and inconclusive particularly with Indigenous youth (Shuter 2011, Kral 2011, Taylor 2012, Cobb \& Graham, 2012, Carlson et al. 2015).

Indigenous youth living in remote communities in Northern Australia are disadvantaged by insufficient access to services in comparison to non-Indigenous youth living in urban and regional centers (Senior 2003, Senior and Chenhall 2012, Kral 2014, Brusse et al. 2014). Indigenous youth living in remote communities’ still practiced traditional law (Senior and Chenhall 2012, Kral 2014) which included beliefs in sorcery and black magic (Reid 1983). An awareness of Indigenous traditional law is vital in dispelling any suspicion (Reid 1983) the community may have of the new 'stranger' (Agar 1996 in DeWalt and DeWalt 2010) prior to entry into the community. The correct 
protocol for engagement begins with seeking out and meeting with the Traditional Owner or senior elders of the community of interest (Marika and Isaacs 1995). Explaining the purpose of the research without scientific terminologies and complex sentences, is key in being understood by a community where English is the fourth or fifth language. When the purpose and benefits of the research to the community is understood, the researcher may request for permission from the Traditional Owners of the community.

Indigenous youth who practice traditional law along with their families follow a strict code of conduct, in relation to their already embedded practices of social relatedness (Brusse et al. 2014) kinship (Marika et al. 1992) and extended networks in order to keep the social, economic and political life of the community in balance (Marika et al. 1992). Engagement with remote Indigenous youth guided by traditional law will avoid unwanted cross cultural misunderstandings and enrichen the relationship between researcher and the community. As Reid (1983) pointed out, "to understand is to show respect”.

The adoption of mobile phones and access to social networking sites such as Facebook, YouTube and Diva Chat (Vodic et al. 2012) within the last ten years (Kral 2011, Taylor 2012, Carlson et al. 2015) had migrated existing offline adolescent behaviours such as bullying and jealousy (Senior and Chenhall 2012) into mobile phone text messages and social media as cyberbullying and intimate partner surveillance (Darvell et al. 2011).

Anonymous social media profiles and phone numbers have been used to spread gossip and intimidate vulnerable youth. The social consequences of cyberbullying, according to my study, had contributed to youth suicide in the community and caused other young people to feel social and emotionally isolated. However, social media and mobile phones are also tools for seeking employment and buying products online that are more affordable. Mobile technology has enabled individuals to manage their finances through Internet banking and transfer money to family living in different communities. Social media and mobile phones enabled Indigenous families to keep in touch with their immediate and extended family members, to live stream funeral ceremonies via video calls, post photos on Facebook of cultural ceremonies, thereby strengthening the Indigenous identity and culture over vast distances.

Positive and negative uses of mobile phones and social media were observed, documented, critiqued and analyzed in depth interviews, over a period of three years. The purpose of this ethnographic study was to understand the lived experiences of Indigenous youth with mobile phones and social media, particularly social networking sites such as Facebook, YouTube and Diva Chat. According to Carlson et al. (2015) and based on the results of my study, Indigenous youth are avid social media user and have always been early adopter of technology. Through this understanding, it is possible that public health and community development practitioners are 
enabled to create resources to support culturally specific programs that address the social determinants (Marmot and Wilkinson 2001) that affect negative online behavior including bullying via text messaging and sexting.

This case study will elaborate on the steps a researcher can take to build a relationship with Indigenous communities and explain how cross-cultural methods of communication is important to enable Indigenous interview participants to openly discuss their thoughts, feelings (Rowse 1996) and discuss the complex elements that play out with the adoption of mobile phones and social media (Shuter 2011). Senior (2003) confirms that there are distinct challenges in sampling and qualitative interviewing in the Indigenous context. One of these distinct challenges is in the circumstantial sharing of information and knowledge subject to variables such as past events, current happenings in the community (Reid 1983, Thoms, 2004; Burbank 2006) and the connection between the interviewer and interviewee in the kinship structure.

The beliefs and interpretations of Indigenous peoples experiences (Reid 1983) explained why the world is as it is and provides them with a framework to evaluate what is going on around them and their relationships with subjects (Marika and Isaacs 1995, McIntosh 2013). It also gave them a sense of identity (Reid 1983, Marika et al. 1992, Ball \& Dagger, 1995,). This worldview can also be called an ideology. Indigenous people have a distinct culture and ideology. Ideology regardless of culture and ethnicity is related to ideas and beliefs. These ideas and beliefs may vary from individual to individual, states Taft (1975) and confirmed by Reid (1983), even though they come from the same community and follow a traditional and communal lifestyle (Senior and Chenhall 2012).

In order to document and understand Indigenous attitudes, beliefs and practices with mobile phones and social media, it may be useful for the researcher to use ethnography; a methodology with a non-reductionist view of the world (Baum 1995) capable of capturing the lived experiences of young people, their context and gain and in depth understanding in the field (Senior and Chenhall 2012). Qualitative researchers use the ethnographic method to understand Indigenous and nonIndigenous people, “...their cultures, their meanings, and their ways of life” according to Liamputtong and Ezzy (2005). Ethnography may help formulate sensible questions in the native language for further study where quite often questionnaires are formulated from a researcher or non-Indigenous perspective and may therefore make no sense or are culturally inappropriate to Indigenous people (Coreil, cited in Liamputtong 2005).

It is important for researchers conducting qualitative interviews with Indigenous participants to be aware of the Indigenous context; their history and impact of colonialism and dispossession, 
their kinship structure and relationship to land and sea. With an awareness and knowledge of the Indigenous context, researchers can then apply them to experiences, ideas, belief, attitudes and events that contribute to theoretical rigor which Mason (1996) observed is essential to qualitative interviewing.

\section{Methods in Action}

The Indigenous communities and individuals in the community are often interchangeable entities. Depending on the status, role or authority of individual, they may represent the concerns of the community and act as their spokesperson and leader (Morphy \& Morphy, 1984). It is important that Indigenous leaders and senior elders in the community are consulted first and permission, given to conduct interviews, before turning to participant sampling. Working with a cultural advisor is highly recommended and in some communities, the traditional laws of Indigenous people require such cultural protocols to be followed.

Cultural advisors are often senior elders or traditional owners who can be identified by contacting the local Indigenous council or Indigenous corporation in charge of managing the affairs of the community. Seeking advice from the Land Council and requesting a contact person who is a cultural advisor may be another option. It is not uncommon to have Indigenous council members or Indigenous corporation board members who also act as cultural advisors to have their contact details on the websites of their organizations.

The researcher should provide ample time for the individuals in the community to engage and become acquainted with them. The approach that I applied was to become acquainted with the Indigenous communities governing structures. I identified what geographical areas belong to which clan and who their Traditional Owners were. As Indigenous leaders are often busy with the socioeconomic and political life of the community, they are not easy to meet. Making an appointment and being patient but also following up with their executive assistants every week is important.

Engagement with individual community members is mostly opportunistic but can be planned and nurtured through observation and an understanding of what contributions a researcher can make to the community. I identified a football team in the community which needed a 'water boy' to organize and provide water to the football players during training and matches. I also socialized with the football players during weekends. 
The researcher's visibility in public is key in forming connections and relationships with Indigenous youth and their senior elders in various contexts, such as sporting activities, social events and traditional ceremonies, the researcher's trust and rapport with the community of interest is nurtured. The researcher may open up as many opportunities for the community and interested individuals to observe and connect with them in their daily life and work by going camping, fishing, becoming Facebook friends and just being a support during funeral ceremonies.

Without the formality of an office, an appointment or schedule, the researcher's casual attitude towards building connections and networks is essential in order to dispel suspicion (Reid 1983) fear or a post-colonial agenda, normally felt to any new comer (DeWalt \& DeWalt 2010). The researcher can achieve this by spending time in public spaces where Indigenous people and their families frequent for their daily business, work and entertainment, reinforcing relationships and getting to know the community beyond the research question. These public places are for example; the football field, the ceremonial grounds, the local food shop, the pub or in the vicinity of the local bank.

A researcher participating in the life of the community is an interesting but not an easy task. Once accepted into the community and as 'family' or 'kin', the researcher is expected to fulfill certain responsibilities and look after the welfare of the family to their best ability. One must be able to share their resources, support community members when they are in need and to be open but neutral in conflict. In marginalized Indigenous communities with scarce resources, the researcher is often asked to help out with transportation, organizing food for a funeral, helping with a sporting activities or driving their vehicle on a trip out bush for hunting.

Another useful method to engage potential interview participants is to organize activities which gave something back to the community for their generosity and cooperation in the research. I organized birthday parties and sausage sizzles for the children in the community and followed with a group effort to clean up the community beach. The participation in community life, contributing to the welfare of the researchers' kinship networks with an intention to conduct a study, is not hypocritical or exploitative but is perceived as a reciprocal relationship, central to traditional Indigenous culture and accepted as a form of relationship maintenance. When Indigenous youth and elders engage in a reciprocal relationship, and perceive that there is respect for them, their culture and law according to Williams (1986), who spent several decades as an ethnographer in the same remote community that I went to. The young people are more likely to trust and share their knowledge with a researcher (Senior and Chenhall 2012, Brusse et. Al 2014) who is more integrated in the community then an outsider. 
Living in an Indigenous community amongst the youth and elders, not pressured by time is an important factor that allows a researcher to identify key informants who will share their knowledge and information. The modern researcher today may accomplish this through employing Indigenous people as research assistants and providing them with training and tools for documenting their work. The uses of photography and Dictaphones by Inidigenous research assistants may help circumvent problems of low literacy levels in the community and still provide rich data through the eyes of a local person.

\section{Planning for an interview}

Organizing and planning for an interview may take several week or months. Atleast until the participants you are interested in interviewing are both within your kinship alliance, and has built enough rapport and trust with you to talk about an issue in a formalized process. It is also difficult to plan or to schedule an appointment for an interview in advance with Indigenous people living in remote communities as they have a different relationship to time. To Indigenous people, time is circular and a missed opportunity or meeting will always return. It is also impolite for an Indigenous person to say 'no' and the researcher may misunderstand responses from individuals. It took me a long time to look for body language and tone in interpreting if my potential participants was genuinely interested or feeling uncomfortable to refuse a new acquaintance or newly adopted kin.

Organized interviews generally evolve from opportunistic discussions over a significant period of time, giving the individual a taste of the encounter gaining their confidence that they are in safe hands before gaining official consent. Consent forms should have an explanatory text in the local Indigenous language with a specific line stating that the interview participant can withdraw from the interview at any time. In these circumstances, having an Indigenous cultural advisor to support your efforts will dispel any suspicion individuals may have of your 'questioning' or intentions.

Conducting interviews within an hour and following up with questions over time also allows Indigenous interview participants to reflect on their thoughts in their own time. This approach reduces the chances of your interview participants sharing what they think the researcher wanted to hear (Senior 2003). The more time spent revisiting and talking about the topic reflects the researchers' genuine interest in the interview participant's thoughts and not just a mere symbolic act, which Indigenous people have become accustomed to from researchers in the past. 
Through immersion in a community, a researcher may be able to triangulate his collection of information through informal interviews, in-depth interviews and participant observations. When a contradiction in the data collection arises, the researcher may conduct a more in-depth inquiry with a key informant at a suitable time and place. If the research is again short of time, then seeking feedback from the local Indigenous governing body, council or reference group may be helpful in filling in the gaps in the study but an awareness of Indigenous governing bodies as political machinery is necessary in acknowledging any biases or assumptions.

\section{Interviewing Participants}

\section{In-depth Interviews}

Twelve participants representing a variety of age, gender and perspectives were recruited for in depth interviews in this study. According to the Indigenous traditional law and kinship structure, it is important to interview right individuals according to their status and position in the kinship structure before expanding the sampling of interview participants. There are youth who are invested with the authority and position to share their knowledge and opinions and but the voice of senior elders must be included. Following this cultural protocol, respecting traditional lines of authority and communication is necessary for the sustainability of a study in an Indigenous community. The voice of senior elders alongside young people must equally be reflected in the study. The initial formal interviews were conducted for an average length of one hour and a light snack provided to enable the participant to feel comfortable and focused on the interview. Some Indigenous youth many only have one meal a day and providing some refreshments during the interview is highly recommended.

\section{Gender}

When interviewing women, it is common for their male partner or a trusted female friend to accompany them either at a workplace or at a quiet café. Privacy in this context is important without compromising on the integrity of the interview participant. The Indigenous protocol of engaging with a woman is to ensure that first; she is in the right kinship relationship to the researcher as there could be avoidance relationships, which prohibits the researcher from any form of interaction. Sensitivities around female partners and their engagement with another man (not a 
close member of the family), may only take place with third person present. This avoids cultural misunderstandings, jealousy and interpersonal conflict.

\section{Seating Arrangement}

A casual seating arrangement, seated side by side, in an open or semi open area instead of within the four walls of an office room is deemed culturally appropriate. The main element here is to create a non-confronting, non-interrogating interaction between the researcher and the interview participant. The researcher may conduct the interviews while walking through the bush or on a hunting trip as being connected to 'land and country' places the interviewee in a comfortable environment free from distraction. Interviews may be appropriate in an office space where the interview participant works, allowing them to use a spare office room. In this context, the interviewees colleagues may assume that a general work meeting is taking place.

Although in this study some interviews were conducted during a lunch or coffee break at work, there was a lot of physical movement by the interview participants. Interviewees talked while they made tea or breakfast, while they smoked outside or sometimes even watched a video on the computer. During one session, my interview participants watched a YouTube video quietly while talking to me. Indigenous youth may or may not be comfortable with prolonged eye contact and any feeling of interrogation and formality. Formality in the Indigenous context is based on the kinship structure and dictated by your position relative to your interview participant. Technically, your interview with your 'son' or daughter' will be less formal as opposed to your interview with your 'grandfather' who may be younger to you in age, but still required the right cultural protocol and some formality.

This method is relaxing and allows for a free conversation rather than a serious question and answer format. Sometimes an interview participant would allow for their friend or relative (who are actors in the physical space) to interject and engage in the interview even though the third party would refuse to be included as an interview participant. The information from these third party participants would not be included in the data gathered due to ethical reasons but their participation enabled the actual interview participants to engage in the interview freely. The level of flexibility in the environment and interview location, preferably chosen by the Indigenous interview participant is necessary in enabling a culturally safe environment.

\section{Body Language}


Indigenous people also communicated through hand signs and body language. It can be as subtle as flaring nostrils (meaning; I don’t like you) or as obvious as a wave of a hand with palms facing down (meaning; I don’t want to engage). As my in-depth interviews were semi-structured and allowed for participants to explore their own ideologies and interpretation, taking note of their body language indicated that a question was inappropriate or a non-verbal response was more appropriate than a verbal response which would not be recorded by a Dictaphone. Instead of repeating, paraphrasing or encouraging them to verbalize their answers, it is better to take note of the subtle gestures and to ask and confirm with the interviewee if the question was sensitive and move on to the next question.

When reading the body language of a participant, a researcher must be aware of when the person began to feel comfortable and rapport is established before the more difficult questions that required more reflexivity were posed. A researcher can judge by the tone of voice and take note of how relaxed the participant is seated in their chair (DeWalt \& DeWalt, 2010) to evaluate the general interview environment before proceeding.

\section{Put Yourself in a Scenario When Asking the Question}

The researcher may use personal examples (of me or my family members) preceding the question or describing the reason for the question. This self-attribution allows for the researcher to be more on par with their interviewee and to show the commonalities instead of highlighting the separation between the researcher and the researched or the informant.As often as possible, assure your interviewee that you are not here to make a value judgment or conclude which behavior is good or bad. You can do this by drawing examples from different communities where these issues may exist.

\section{Informal Interviews}

As you engage in different roles and in multiple environments as a community member and researcher, you will be exposed to opportunities to discuss relevant 'in real time' questions or events and receive excellent interpretations and explanations to compliment the data you have been gathering through the in-depth interviews. These moments are rare and the ability to frame a question in a friendly, non-judgmental tone and with a humble posture of learning is highly desirable. 
These opportunities and interactions in an informal manner will enable the researcher to collect more data but also establish a positive reputation within the community as one who practiced culturally appropriate and culturally sensitive research methods. The individual and the community will form an opinion of you as one who is trying to understand a certain aspect of the community in order to benefit the community. The community will soon begin to guide your research (DeWalt \& DeWalt, 2010).

\section{Reaffirming Indigenous Cultural Standpoint}

Indigenous interviewees can be supported to feel comfortable towards researchers' questions and curiosity through an ability to tie the questions in with a cultural standpoint, through reassuring Indigenous people of the intention to respect Indigenous laws. A researcher may explore a topic by first reaffirming the cultural laws and protocol of kinship ties before further asking why certain behaviours happen and what the community or individuals think about it.

Individuals may be apprehensive of giving their personal thoughts as they may not be within specific cultural rights to do so (Morphy, 1984). Although it is within an individual's right as a research participant their ability to discuss issue in the community may be limited and the researcher should be aware of this. A researcher may on the other hand, first establish what the general Indigenous cultural consensus is on the matter, understand what the explanation or interpretation is, and only then proceed to carefully seek what other personal thoughts were available. Indigenous people care cautious about being respectful and not cause the researcher to 'loose face' and be embarrassed.

An individual may, in the light of a sensitive question, proceed to tell you a story or metaphor of what he feels, rather than what he thinks. In this situation it is important to read the body language to know if there is more opportunity for clarification, if it was time to move on to the next question or to end the interview. The researcher will benefit from making a note of this and revisiting the topic at a later opportunity and not discard the information as irrelevant. A discussion with a cultural advisor on this would also be highly recommended.

\section{Asking the questions}

The questions that were used in this study were developed over the course of two in-depth interviews and several informal interviews. This process ensured that the questions were formulated well and could be understood in Indigenous context. 
1. What moiety does the mobile phone belong to? What moiety does social media belong to?

2. How do young people use mobile phones on a daily basis? What do they do with text messaging (SMS) and phone call and how do they decide when to use them?

3. What does the mobile phone and social media mean to Indigenous people and their families, especially the young people?

4. What happens on Facebook and YouTube with family or friends?

5. Do you remember how the mobile phone or Facebook caused problems in the family or community? Can you think of an example?

6. What do you think are the most useful aspects of the mobile phone and social media?

7. Do mobile phones and social media make people jealous or create fights?

\section{What Does All This Mean Methodologically?}

In ethnography, the researcher is an important tool (Senior and Chenhall 2012).

When the researcher is well versed in the aforementioned process, they may proceed to organize and conduct in-depth interviews with volunteers and key informants in the community. The researcher must also be aware that only certain elders and young people have been given the authority to speak and comment and the researcher must ascertain who these people are in the community.

Although the research question is interested in youth, in the Indigenous context, age and seniority is relative in the kinship structure. For example, a 50 year old man may be a nephew to a person in his or her teens. A teenager likewise, may be a grandfather to a much older relative. In the Indigenous context, there are only babies, children and adults i.e. men and women. There is no concept of 'youth' as viewed in the non-Indigenous context. Therefore, interviewing a mix of senior and younger men and women would be both culturally appropriate whilst showing respect to traditional structures of authority and acknowledging traditional law.

\section{Exercises and Discussion Questions}

1. Why is ethnography in an Indigenous context important in research compared to a nonIndigenous community? 
2. Why should a researcher have an awareness and understanding of Indigenous history and culture before conducting their study?

3. What other ways can a time poor research utilize to conduct qualitative interview in the Indigenous context?

\section{Further Reading}

Agar, M.H., 1996. The professional stranger: An informal introduction to ethnography

Baum, F. (1995). Researching public health: behind the qualitative-quantitative methodological debate. Social Science \& Medicine, 40(4), 459-468.

Taft, R., Dawson, J. L., \& Beasley, P. (1970). Attitudes and social conditions: essays (Vol. 2). Canberra: Australian National University Press.

Thomson, D. F., \& Peterson, N. (1983). Donald Thomson in Arnhem Land. South Yarra, Vic.: C. O” Neil.

Vodic A, Senior K, Dwyer B, Szybiak P, (2012). A remote change? The potential for Indigenous students to participate in online learning in remote communities in the Northern Territory, Charles Darwin University.

\section{References}

Agar, M.H., 1996. The professional stranger: An informal introduction to ethnography.

Ball, T., \& Dagger, R. (2006). Political ideologies and the democratic ideal. Pearson Longman.

Berger, W., \& Mau, B. (2009). Glimmer. New York. The Penguin Press.

Burbank, V. (2006). From Bedtime to On Time: Why Many Aboriginal People Don’t Especially Like Participating in Western Institutions 1. In Anthropological Forum (Vol. 16, No. 1, pp. 320). Routledge.

Brusse, C., Gardner, K., McAullay, D. and Dowden, M., 2014. Social media and mobile apps for health promotion in Australian indigenous populations: scoping review. Journal of medical Internet research, 16(12). 
Carlson, B.L., Farrelly, T., Frazer, R. and Borthwick, F., 2015. Mediating tragedy: facebook, aboriginal peoples and suicide. Australasian Journal of Information Systems, 19.

Coreil, J., Augustin, A., Holt, E., \& Halsey, N. A. (1989). Use of ethnographic research for instrument development in a case-control study of immunization use in Haiti. International Journal of Epidemiology, 18(Supplement 2), S33-S37.

Cobb, N. K., \& Graham, A. L. (2012). Health behavior interventions in the age of Facebook. American journal of preventive medicine, 43(5), 571-572.

Darvell, M.J., Walsh, S.P. and White, K.M., 2011. Facebook tells me so: Applying the theory of planned behavior to understand partner-monitoring behavior on Facebook. Cyberpsychology, Behavior, and Social Networking, 14(12), pp.717-722.

DeWalt, K. M., \& DeWalt, B. R. (2010). Participant observation: A guide for fieldworkers. Rowman Altamira.

Eysenbach, G., 2008. Medicine 2.0: social networking, collaboration, participation, apomediation, and openness. Journal of medical Internet research, 10(3).

Fessler JW, 1980. Public Administration theory and practice. Englewood Cliffs: Prentice-Hall

Gerritsen R, 1982. Outstations, Differing Interpretations and Policy implications in Loveday

Kral, I., 2011. Youth media as cultural practice: Remote Indigenous youth speaking out loud. Australian Aboriginal Studies, (1), p.4.

Kral, I., 2014. Shifting perceptions, shifting identities: Communication technologies and the altered social, cultural and linguistic ecology in a remote indigenous context. The Australian Journal of Anthropology, 25(2), pp.171-189.

McIntosh, I.S., 2013. 6. Unbirri’s pre-Macassan legacy, or how the Yolngu became black. Macassan history and heritage: journeys, encounters and influences/Marshall Clark, p.95.

Marika, R., Ngurruwutthun, D. and White, L., 1992. Always Together, Yaka Gäna: Participatory Research at Yirrkala as Part of the Development of a Yolngu Education. Convergence, 25(1), p.23. 
Marika, R., Ngurruwutthun, D. and White, L., 1992. Always Together, Yaka Gäna: Participatory Research at Yirrkala as Part of the Development of a Yolngu Education. Convergence, 25(1), p.23.

Marmot, M. and Wilkinson, R.G., 2001. Psychosocial and material pathways in the relation between income and health: a response to Lynch et al. Bmj, 322(7296), pp.1233-1236.

Mason, J. (2002). Qualitative researching. Sage.

Morphy, H. and Morphy, F., 1984, 'The "myths” of Ngalakan history: ideology and images of the past in Northern Australia', Man, 19: 459-478.

Liamputtong, P., \& Ezzy, D. (2005). Qualitative research methods.

Rowse, T. (1996). Traditions for health: studies in Aboriginal reconstruction. North Australia Research Unit, The Australian National University.

Senior KA, (2003), A Gudbala Laif? Health and Wellbeing in a remote Aboriginal community what are the problems and where lies responsibility. University of Wollongong.

Senior, K.A. and Chenhall, R.D., 2012. Boyfriends, babies and basketball: present lives and future aspirations of young women in a remote Australian Aboriginal community. Journal of Youth Studies, 15(3), pp.369-388.

Shuter, R., 2011. Introduction: New media across cultures-prospect and promise. Journal of International and Intercultural Communication, 4(4), pp.241-245.

Taft, R 1975. Attitudes of Western Australians towards Aborigines in Ronald Taft, John LM Dawson and Thoms P, (2004), Driven by time. Time orientation and Leadership. Greenwood Publishing Group. Printed in the United States of America. Pg 31.

Taylor, A., 2012. Information communication technologies and new Indigenous mobilities? Insights from remote Northern Territory Communities. Journal of rural and Community Development, 7(1), pp.59-73.

Thomson, D. F., \& Peterson, N. (1983). Donald Thomson in Arnhem Land. South Yarra, Vic.: C. O" Neil. 
Vodic A, Senior K, Dwyer B, Szybiak P, (2012). A remote change? The potential for Indigenous students to participate in online learning in remote communities in the Northern Territory, Charles Darwin University.

Williams, N. M. (1986). The Yolngu and their land: a system of land tenure and the fight for its recognition. Stanford University Press. 